\title{
CHRONIC OBSTRUCTIVE PULMONARY DISEASE RISK AND SMOKING CESSATION CHANGES INDUCED BY CHRNA5-A3 AND CHRNB3-A6 VARIATION IN A CHINESE MALE POPULATION
}

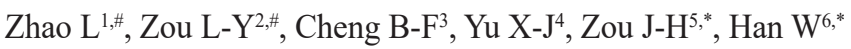

*Corresponding Authors: Dr. Wei Han, Department of Pulmonary Medicine, Qingdao Municipal Hospital, Qingdao University, No. 5 Donghai Mid Road, Qingdao, People's Republic of China. Tel: +86-1856185-7838. E-mail: sallyhan1@163.com. And: Dr. Jian-Hong Zou, Center of Diseases Control of Qingdao Shi-Bei District, No. 3 Deping Road, Qingdao, People's Republic of China. Tel: +86-185-6185-7599. E-mail: 277517366@qq.com
\end{abstract}

"Long Zhao, Ling-Yan Zou contributed equally to this study.

\begin{abstract}
Most studies in the field of CHRNA5-A3 and $C H R N B 3-A 6$ have only focused on lung cancer risk; however, the associations with chronic obstructive pulmonary disease (COPD) risk and smoking cessation is less understood, particularly in the Chinese male population. In this study, samples from 823 male patients with COPD (non smokers: 416; still smoking: 407) and 435 smoking male healthy control subjects were performed with DNA extraction and single nucleotide polymorphism (SNP) genotyping. We studied three SNPS in two genes, namely rs667282 and rs3743073 in CHRNA5-A3 and rs4950 in $C H R N B 3-A 6$, and their distributions in the three groups are not statistically different $(p>0.05)$. We grouped COPD patients according to whether they had successfully quit smoking, the CT genotype of rs667282 demonstrated association with an increased rate of successful smoking
\end{abstract}

\footnotetext{
${ }^{1}$ Department of Clinical Laboratory, Qingdao Municipal Hospital, Qingdao University, Qingdao, Shandong Province, People's Republic of China

${ }^{2}$ Intensive Care Unit, The First Affiliated Hospital of Gannan Medical College, Ganzhou, Jiangxi Province, People's Republic of China

${ }^{3}$ Department of Respiratory and Critical Care, Yangquan Coalmine Group General Hospital, Yangquan, Shanxi Province, People's Republic of China

${ }^{4}$ Department of Central Laboratory, Qingdao Municipal Hospital, Qingdao University, Qindao, Shandong Province, People's Republic of China

${ }^{5}$ Center of Diseases Control of Qinegdao Shi-Bei District, Qingdao, Shandong Province, People's Republic of China

${ }^{6}$ Department of Respiratory and Critical Care II, Qingdao Municipal Hospital, Qingdao University, Qingdao, People's Republic of China
}

cessation compared with the TT genotype [adjusted odds ratio $(\mathrm{OR})=0.54,95 \%$ confidence interval $(95 \% \mathrm{CI})=$ $0.37-0.7, p<0.001)$; rs4950 AG genotypes were distinctly associated with increased rates of successful smoking cessation (adjusted $\mathrm{OR}=0.55,95 \% \mathrm{CI}=0.40-0.76, p<0.001$ ). The effect is significant under the assumption of an over dominant mode of inheritance (adjusted $\mathrm{OR}=0.58,95 \%$ $\mathrm{CI}=0.43$ to $0.79, p<0.001)$. No significant difference in rs3743073 was found $(p>0.05)$. Our findings confirmed the hypothesis that $C H R N A 5-A 3$ and $C H R N B 3-A 6$ variation are not associated with the risk of COPD. We found CHRNA5-A3 and CHRNB3-A6 were significantly associated with successful smoking cessation in smoking COPD patients.

Keywords: Chronic obstructive pulmonary disease (COPD); Single nucleotide polymorphisms (SNPs); Smoking cessation.

\section{INTRODUCTION}

Investigating chronic obstructive pulmonary disease (COPD) and smoking cessation is a continuing concern within pulmonology. Its mortality $\underline{i}$ expected to be ranked fourth in the world by 2030 [1]. It is generally believed that smoking is the main risk factor for COPD development, however, only a fraction ( $20.0 \%)$ of smokers develop COPD [2]. This suggests that individual susceptibility is caused by genetic factors. Previous genetic studies have shown that nicotine-dependence is a complex genetic disorder [3]. We believe that genes related to nicotinedependence may affect the development of COPD. In addition, nicotine-dependence can be considered as the most significant factor for smoking cessation [4]. 
Nicotinic acetylcholine receptors, or nAChRs, are receptor polypeptides that respond to the neurotransmitter acetylcholine [5]. Nicotine, a major component of tobacco, is the main cause of tobacco addiction that acts through nAChRs. At present, genome-wide association studies have proved that several single nucleotide polymorphisms (SNPs) (rs1051730, rs16969968, rs8034191 and rs4950) in two nAChRs (CHRNA5-A3 and CHRNB3-A6) subunit coding gene clusters are associated with nicotine-dependence and lung cancer [6-10]. In addition, according to the HapMap database (https://www.ncbi.nlm.nih.gov/probe/ docs/ projhapmap/) and a study by Wu et al. [11], there is no report that these three SNP variants have been found in Asian populations. These variants have little risk of lung cancer and nicotine-dependence in the Chinese population. Surprisingly, the results of two independent studies show that rs667282 and rs3743073 in CHRNA5-A3 will affect the risk of lung cancer in Chinese people [11,12]. Moreover, several independent studies have shown that rs4950 in CHRNB3-A6 is with smoking behavior, and this shows that they have a certain role in people who have difficulty in quitting smoking and people who are carcinogenic due to smoking $[9,10]$. Thus far, no research has reported if the three SNPs are also associated with smoking-related COPD and smoking cessation. Therefore, this study aimed to investigate the correlation between the three SNPs (rs667282, rs3743073 and rs4950) and smoking cessation in the Chinese male population.

\section{MATERIALS AND METHODS}

Research Participants. From January 2017 to May 2018, we recruited patients admitted to the Second Ward of Respiratory Department of Qingdao Municipal Hospital, Qingdao, Shandong Province, People's Republic of China (PRC). The study consisting of 823 male smokers with COPD (407 patients with COPD who failed to quit smoking and 416 non smokers with COPD $\geq 1$ year) and 435 healthy male smokers as control subjects. All subjects were recruited from the Smoking Cessation Clinic and the Medical Examination Department of Qingdao Municipal Hospital. Demographic information, including age, body mass index (BMI), and detailed circumstances of smoking, was collected in interviews conducted by trained medical doctors. Those smoking at least 20 packs in their life, or smoking at least one cigarette a day for more than 1 year were classified a smokers, non smokers were classified as having quit smoking $\geq 1$ year. Smoking COPD subjects meet the following criteria: for those who still smoke or have quit smoking, physician-diagnosed COPD, pulmonary function test showing post-bronchodilator forced expiratory volume (FEV) in 1 second (FEV1)/forced vi- tal capacity (FVC) of less than $70.0 \%$ and FEV1 of less than $80.0 \%$ predicted in the Global Initiative for COPD 2015 (GOLD 2015; https://glodcopd/org/). Subject exclusion criteria: definite diagnosis of lung cancer, asthma or smoking-related cancer. Cases were matched according to age, BMI and smoking history. The study was approved by Qingdao Municipal Hospital Ethics Committee (approval number: KYLL2010058). All patients participating in the program signed an informed consent form.

Analysis. Blood samples of all participants were collected. Using the DNA extraction kit (Tiangen Biotech Co. Ltd., Beijing, PRC) to extract the genomic DNA of the subjects. Genotyping was carried out commercially using Sequenom MassARRAY ${ }^{\circledR}$ via Beijing Genomic Institute (BGI) (Shenzhen, PRC) [13]. In order to ensure the repeatability and consistency of the test, we randomly selected $5.0 \%$ of the samples for a second test. In addition, in order to further verify the accuracy of the BGI results, we also genotyped some samples by direct sequencing or restriction enzyme digestion.

Statistical Analysis. The $t$-test was used to confirm the difference in population characteristics and gene distribution between the experimental group and the control group. The $\chi^{2}$ test was used to compare the demographic characteristics of the case group and the control group. The correlation between each SNP and the risk of smoking and nicotine-dependence in COPD patients was evaluated by a logistic regression model, which adjusted the age, BMI, current smoking status and the number of packages per year for long-term smokers. Age, BMI, current smoking status and pack-years of the number of cigarettes smoked per year, including those who quit and those who are currently smoking, were analyzed in a hierarchical manner to assess whether there was any difference between these subgroups. All statistical analyses adopted a two-sided test, and a $p$ value of $<0.05$ was considered to be statistically significant. The Statistical Package for the Social Sciences (SPSS) version 22 (IBM® SPSS; www.ibm.com/SPSSStatistics/) was used for all statistical analysis.

\section{RESULTS}

Demographic Characteristics. As shown in Table 1, the demographics and clinical feature distribution of the subjects show that there are significant differences in age, daily smoking volume and the years of smoking distribution between COPD smoking group, COPD absent smoking group, and smoking without COPD group ( $p$ $0.001, p<0.001$ and $p 0.001$ ). For still smoking patients with COPD and non smoking patients with COPD, we discovered marked differences with respect to age and the years of smoking (both $p$ 0.001). These differences were 
Table 1. The demographic characteristics of the studied subjects. (Results are presented as mean \pm SD.)

\begin{tabular}{|c|c|c|c|c|c|c|}
\hline \multirow[t]{2}{*}{ Characteristics } & \multicolumn{2}{|c|}{ Male Smokers } & \multirow[b]{2}{*}{$p$ Value $^{\mathrm{a}}$} & \multicolumn{2}{|c|}{ Male COPD Patients } & \multirow[b]{2}{*}{$p$ Value } \\
\hline & $\begin{array}{c}\text { COPD Patients } \\
(n=256)\end{array}$ & $\begin{array}{c}\text { Healthy Controls } \\
(n=435)\end{array}$ & & $\begin{array}{c}\text { Still Smoking } \\
(n=256)\end{array}$ & $\begin{array}{c}\text { Non Smoking } \\
(n=410)\end{array}$ & \\
\hline Age (years) & $67.6 \pm 11.1$ & $57.1 \pm 13.2$ & $<0.001$ & $67.6 \pm 11.1$ & $70.7 \pm 8.2$ & $<0.001$ \\
\hline BMI (years) & $21.5 \pm 3.5$ & $21.8 \pm 3.4$ & 0.13 & $21.0 \pm 2.9$ & $28.8 \pm 3.1$ & 0.220 \\
\hline $\begin{array}{l}\text { Smoking variables: } \\
\text { Cigarettes/day }\end{array}$ & $27.0 \pm 15.1$ & $19.7 \pm 11.7$ & $<0.001$ & $27.0 \pm 15.1$ & $21.2 \pm 9.7$ & $<0.001$ \\
\hline Years smoking & $40.2 \pm 9.9$ & $31.4 \pm 14.7$ & $<0.001$ & $40.2 \pm 9.9$ & $34.9 \pm 13.4$ & $<0.001$ \\
\hline Post-FEV1 predicted & $58.0 \pm 5.6$ & $104.7 \pm 9.6$ & $<0.001$ & $58.0 \pm 5.6$ & $59.1 \pm 16.2$ & 0.0352 \\
\hline Post-FEV1/FVC ratio & $52.7 \pm 8.7$ & $78.5 \pm 5.6$ & $<0.001$ & $52.7 \pm 8.7$ & $53.9 \pm 8.6$ & 0.056 \\
\hline $\begin{array}{l}\text { GOLD status: } \\
\text { Stage I (mild) }\end{array}$ & 114 & - & - & 114 & 133 & - \\
\hline Stage II (moderate) & 120 & - & - & 120 & 138 & - \\
\hline Stage III (severe) & 98 & - & - & 98 & 121 & - \\
\hline Stage IV (very severe) & 75 & - & - & 75 & 24 & - \\
\hline
\end{tabular}

COPD: chronic obstructive pulmonary disease; FEV1: forced expiratory volume in 1 second; FVC: forced vital capacity.

${ }^{a}$ A $p$ value of $<0.05$ was considered to be statistically significant.

adjusted in subsequent logistic regression analyses. By comparing the ratios of FEV1 and FEV1/FVC, smoking COPD patients are significantly worse than the control group, and these findings are similar in still smoking patients with COPD and non smoking patients with COPD. In the COPD patients, pulmonary function was classified as mild, moderate, severe, and very severe (30.0, 31.4, 26.6 and $12.0 \%$, respectively).

Association Between Gene Polymorphisms and COPD Risk in Smokers. We observed all three SNPs were in Hardy-Weinberg equilibrium in the control group ( $p$ 0.05). We genotyped the three SNPs (rs3743073, rs667282 and rs4950) in cases and controls and the results are presented in Table 2. No significant associations were found between rs3743073, rs667282 and rs4950 genotypes and COPD risk after adjusting for age, BMI and smoking status.

Association Between Gene Polmorphisms and Smoking Cessation in COPD Patients. Associations between gene polymorphisms and smoking cessation in COPD are shown in Table 3. The genotypes of rs667282 and rs4950 showed significant difference between cases and controls without adjustment for potential confounding factors (age, BMI and smoking pack-years). We adjusted for potential confounding factors by means of logistic regression, and then calculated the odds ratios (ORs). The CT genotype of rs667282 demonstrated association with an increased rate of successful smoking cessation compared with the TT genotype [adjusted OR $=0.54,95 \%$ confidence interval

Table 2. Association of genotype distribution of three SNPs with COPD risk in the patients and controls.

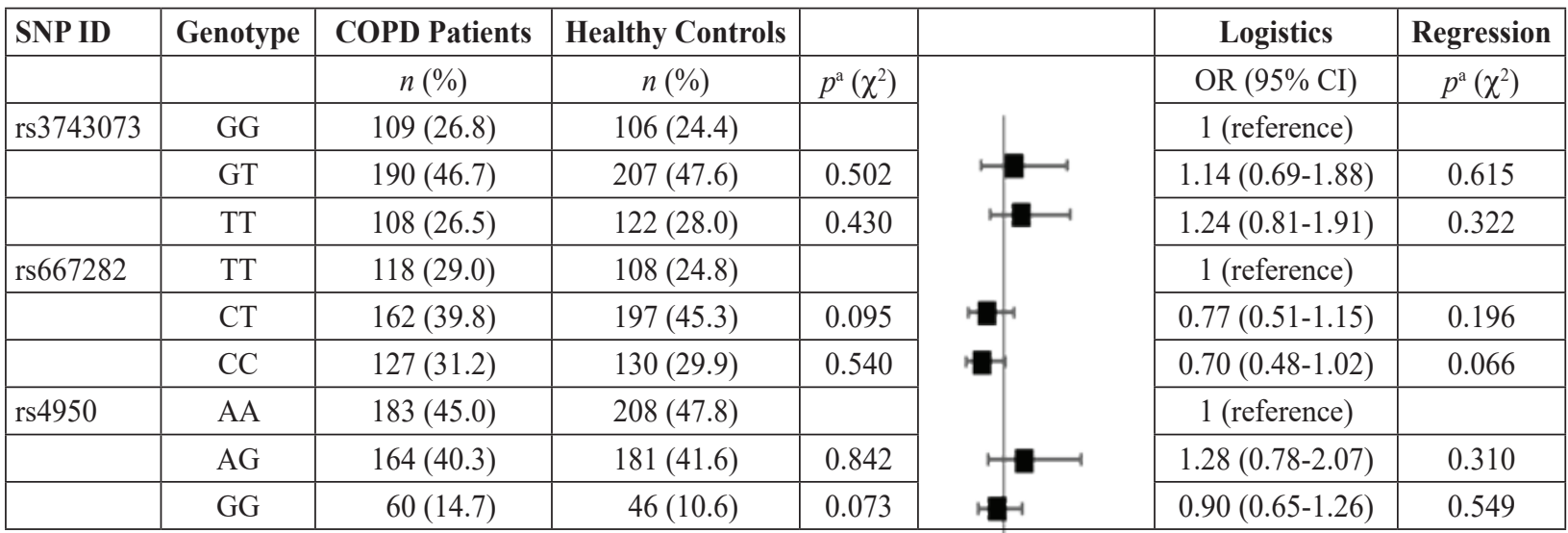

SNPs ID: single nucleotide polymorphisms identification; COPD: chronic

obstructive pulmonary disease; OR: odds ratio; 95\% CI: 95\% confidence interval.

a A $p$ value of $<0.05$ was considered to be statistically significant. 
Table 3. Association of genotype distribution of three SNPs with smoking cessation in still smoking and non smoking subjects.

\begin{tabular}{|c|c|c|c|c|c|c|}
\hline SNP ID & Genotype & Still Smoking & Non Smoking & & Logistics & Regression \\
\hline & & $n(\%)$ & $n(\%)$ & $p^{\mathrm{a}}\left(\chi^{2}\right)$ & OR $(95 \% \mathrm{CI})^{\mathrm{b}}$ & $p^{\mathrm{a}}\left(\chi^{2}\right)$ \\
\hline \multirow[t]{3}{*}{ rs3743073 } & GG & $109(26.8)$ & $92(22.1)$ & & 1 (reference) & \\
\hline & GT & $190(46.7)$ & $221(53.1)$ & 0.063 & $1.01(0.66-1.53)$ & 0.975 \\
\hline & TT & $108(26.5)$ & $103(24.8)$ & 0.093 & $0.73(0.51-1.05)$ & 0.731 \\
\hline \multirow[t]{6}{*}{ rs667282 } & TT & $118(29.0)$ & $92(22.1)$ & & 1 (reference) & \\
\hline & $\mathrm{CT}$ & $162(39.8)$ & $205(49.3)$ & 0.005 & $0.54(0.37-0.77)$ & 0.001 \\
\hline & $\mathrm{CC}$ & $127(31.2)$ & $119(28.6)$ & 0.330 & $0.75(0.50-1.10)$ & 0.142 \\
\hline & $\mathrm{CT}+\mathrm{CC}$ & $289(71.0)$ & $324(77.9)$ & 0.024 & $0.61(0.44-0.86)$ & 0.004 \\
\hline & $\mathrm{TT}+\mathrm{CC}$ & $245(60.2)$ & $211(50.7)$ & - & - & - \\
\hline & $\mathrm{CT}$ & $162(39.8)$ & $205(49.3)$ & 0.006 & $0.61(0.45-0.83)$ & 0.001 \\
\hline \multirow[t]{6}{*}{ rs4950 } & AA & $183(45.0)$ & $143(34.3)$ & & 1 (reference) & \\
\hline & $\mathrm{AG}$ & $164(40.3)$ & $217(52.2)$ & 0.001 & $0.55(0.40-0.76)$ & $<0.001$ \\
\hline & GG & $60(14.7)$ & $56(13.5)$ & 0.412 & $0.85(0.54-1.32)$ & 0.462 \\
\hline & $\mathrm{AG}+\mathrm{GG}$ & $224(55.0)$ & $273(65.7)$ & 0.002 & $0.62(0.46-0.83)$ & 0.001 \\
\hline & $\mathrm{AA}+\mathrm{GG}$ & $243(59.7)$ & $199(47.8)$ & - & - & - \\
\hline & $\mathrm{AG}$ & $164(40.3)$ & $217(52.2)$ & 0.001 & $0.58(0.43-0.79)$ & $<0.001$ \\
\hline
\end{tabular}
pulmonary disease; OR: odds ratio; $95 \% \mathrm{CI}$ : 95\% confidence interval.

a A $p$ value of $<0.05$ was considered to be statistically significant.

$(95 \%$ CI $)=0.37-0.7, P=0.001]$. The rs4950 AG genotypes were distinctly associated with increased rates of successful smoking cessation (adjusted $\mathrm{OR}=0.55,95 \% \mathrm{CI}=0.40-0.76$, $p$ 0.001). The effect is significant under the assumption of an over dominant mode of inheritance (adjusted $\mathrm{OR}=0.58$, $95 \% \mathrm{CI}=0.43-0.79, p 0.001)$, while the similar significant differences in rs3743073 was not found ( $p$ 0.005).

We further observed the suspicious influence factor of CHRNA5-A3 (rs 667282) and CHRNB3-A6 (rs4950) on smoking cessation, stratified by age, cigarettes per day (CPD) and initiation age smoking (Table 4 and Table 5, respectively). As show in Table 4, the success rate of quitting smoking increased for older subjects ( $>60$ years) (OR $=0.66,95 \% \mathrm{CI}=0.45-0.99, p=0.042)$ and light smokers
$(\mathrm{CPD} \leq 20)(\mathrm{OR}=0.58,95 \% \mathrm{CI}=0.39-0.86, p=0.007)$, accompanied by rs667282 CT genotype. In Table 5, we show that the increased rate of successful smoking cessation with rs4950 AG genotypes was more notable in light smokers $(\mathrm{CPD} \leq 20)(\mathrm{OR}=0.65,95 \% \mathrm{CI}=0.45-0.92, p=$ $0.016)$. There was no significant difference in the stratification of age and initiation age smoking.

Association of CHRNA5-A3 and CHRNB3-A6 Poly-morphisms with the GOLD Stage of COPD Patients. The association of rs667282 and rs4950 polymorphisms with the GOLD stage of COPD patients are exhibited in Table 6. In our study, The CT genotype of rs667282 and the AG genotype of rs4950 showed a weak association with the GOLD stage of COPD patients.

Table 4. Stratification analysis of rs667282 genotypes by selected variables in still smoking and non smoking subjects.

\begin{tabular}{|c|c|c|c|c|c|c|c|}
\hline \multicolumn{2}{|c|}{ Category } & \multicolumn{2}{|c|}{ Still Smoking } & \multicolumn{2}{|c|}{ Non Smoking } & \multirow[b]{2}{*}{ OR $(9 \% \mathrm{CI})$} & \multirow[b]{2}{*}{$p$ Value } \\
\hline & & TT & CT & TT & CT & & \\
\hline \multirow[t]{2}{*}{ Age (years) } & $<60$ & 39 & 53 & 22 & 45 & $0.66(0.35-1.28)$ & 0.221 \\
\hline & 60 & 80 & 109 & 78 & 160 & $0.66(0.45-0.99)$ & 0.042 \\
\hline \multirow[t]{2}{*}{ Cigarettes/Day } & $<20$ & 84 & 104 & 77 & 164 & $0.58(0.39-0.86)$ & 0.007 \\
\hline & 20 & 35 & 58 & 23 & 41 & $0.93(0.48-1.80)$ & 0.829 \\
\hline \multirow[t]{2}{*}{ Initial age smoking } & $<20$ years & 75 & 114 & 66 & 149 & $0.67(0.45-1.02)$ & 0.059 \\
\hline & $>20$ years & 44 & 48 & 34 & 56 & $0.66(0.37-1.20)$ & 0.171 \\
\hline
\end{tabular}


Table 5. Stratification analysis of rs4950 genotypes by selected variables in still smoking and non smoking subjects.

\begin{tabular}{|c|c|c|c|c|c|c|c|}
\hline \multicolumn{2}{|c|}{ Category } & \multicolumn{2}{|c|}{ Still Smoking } & \multicolumn{2}{|c|}{ Non Smoking } & \multirow[b]{2}{*}{ OR $(9 \% \mathrm{CI})$} & \multirow[b]{2}{*}{$p$ Value } \\
\hline & & AA & $\mathrm{AG}$ & AA & $\mathrm{AG}$ & & \\
\hline \multirow[t]{2}{*}{ Age (years) } & $<60$ & 52 & 76 & 28 & 40 & $1.02(0.56-1.86)$ & 0.940 \\
\hline & $>60$ & 128 & 106 & 118 & 174 & $1.22(0.86-1.73)$ & 0.260 \\
\hline \multirow[t]{2}{*}{ Cigarettes/Day } & $<20$ & 116 & 114 & 106 & 161 & $0.65(0.45-0.92)$ & 0.016 \\
\hline & $>20$ & 64 & 68 & 40 & 53 & $0.80(0.47-1.37)$ & 0.417 \\
\hline \multirow[t]{2}{*}{ Initial age smoking } & $<20$ years & 113 & 116 & 94 & 133 & $0.73(0.50-1.05)$ & 0.089 \\
\hline & $>20$ years & 67 & 66 & 52 & 81 & $0.63(0.39-1.03)$ & 0.064 \\
\hline
\end{tabular}

Table 6. Association of rs667282 and rs4950 polymorphisms with the GOLD stage of COPD patients.

\begin{tabular}{|l|c|c|c|c|c|c|c|c|}
\hline Category & \multicolumn{2}{|c|}{ Still Smoking } & OR $\mathbf{( 9 5 \%}$ CI) & \multicolumn{1}{c|}{ Value } & Non Smoking & OR (95\% CI) & $\boldsymbol{p}$ Value \\
\hline rs667292 & TT & CT & & & TT & CT & & \\
\hline GOLD status: I and II & 71 & 93 & reference & & 55 & 126 & reference & \\
\hline GOLD status: III and IV & 48 & 70 & $0.90(0.57-1.45)$ & 0.661 & 45 & 79 & $1.31(0.80-2.12)$ & 0.281 \\
\hline rs4950 & AA & AG & & & AA & AG & & \\
\hline GOLD status: I and II & 102 & 110 & reference & & 104 & 136 & reference & \\
\hline GOLD status: III and IV & 78 & 82 & $1.03(0.68-1.55)$ & 0.903 & 42 & 78 & $0.70(0.45-0.11)$ & 0.129 \\
\hline
\end{tabular}

OR: odds ratio; $95 \% \mathrm{CI}$ : $95 \%$ confidence interval.

\section{DISCUSSION}

The purpose of our study was to investigate whether SNPs in the two gene clusters are related to COPD and smoking cessation in the Chinese population. We did not find a significant association between the SNPs and COPD risk in the smoking subjects. However, the SNP rs667282 in CHRNA3-A5 and rs4950 in CHRNB3-A6 showed a significant association with an increased rate of successful smoking cessation, in the Chinese COPD population, but the rs3743073 did not show an association with smoking cessation. These results suggest that the polymorphisms of CHRNA3-A5 and CHRNB3-A6 may play a key role in successful smoking cessation in Chinese COPD patients. As far as we know, this is the first study to reveal the relationship between SNP in CHRNA3-A5 and CHRNB3-A6 genes and COPD and smoking cessation.

Nicotinic acetylcholine receptor $(C H R N)$ genes code nAChRs, which bind to nicotinic that cause nicotinic dependence and smoking-related diseases. Recently, the associations of rs 3743073 and rs667282 in CHRNA3-A5 and rs4950 in $C H R N B 3-A 6$ with tobacco consumption and lung cancer risk have been discovered $[11,12,14,15]$. Chronic smoking and environmental factors contribute to the development of lung cancer. Some studies show that COPD is a risk factor for lung cancer, even in early stage COPD [16-18]. The association between CHRNs and COPD and lung cancer has been confirmed $[11,19]$. We speculate that rs3743073, rs667282 and rs4950 may be associated with COPD in smokers, but we did not study the role of CHRN genetic variants with lung cancer. In addition, consistency with the conclusions of the study of Budulac et al. [20], $C H R N$ gene variants are closely correlated with smoking habits, but do not directly cause COPD.

The main reason that smokers are unable to quit is nicotine dependence, and nicotine dependence has a relationship with a series of diseases, especially COPD [21]. Smoking cessation is the only evidence-based intervention, which can reduce the risk of developing COPD and slow down the accelerated decline of lung function in patients with COPD [21]. Nicotine dependence and smoking cessation are influenced by genetic factors [14,15,22,23]. The study of Pérez-Rubio et al. [24] demonstrated that rs6313 in HTR2A increased the risk for the early onset of smoking. Nicotine dependence is strongly associated with the decreased rate of initial abstinence and the high risk of transition from lapse to relapse [25]. Gold and Lerman [26] found that nicotine dependence and smoking cessation have their respectively unique regulatory genes. Although these phenotypes may share some genetic effects, it cannot be considered that the genetic association of nicotine dependence will translate into smoking cessation or vice versa [26]. Studies have shown that $C H R N s$ are strongly associated with nicotine dependence [14,15,21,27]. Given 
the limited genetic contributions in nicotine dependence and smoking cessation, more research of the genetic study of smoking cessation is needed.

We observed a significant association between the SNPs rs667282, and rs4950 and smoking status (still smoking vs. non smoking: $n=823$ ), indicating CHRNs variants are associated with smoking cessation. Our results agree with previous studies which show CHRNs were significantly related to smoking cessation in different populations [28,29]. Moreover, a number of other studies concluded that association of CHRNs and smoking cessation is limited [30,31]. For instance, Freathy et al. [31] found that among Caucasian smokers, there was no significant relationship between CHRNA5-A3-B4 gene variation and smoking cessation treatment results. These different conclusions may come from different groups of people for each study, but further investigation is needed.

In the stratified study, the relationship between the rs667282 genotype and successful smoking cessation was more obvious in older subjects and lighter smokers. It is remarkable that the successful smoking cessation was more likely in older smokers than in younger smokers. The result agrees with study of Chen et al. [32], which reported on the CHRNA5-CHRNA3-CHRNB4 haplotypes. Compared with low-risk haplotype (H1), high-risk haplotype (H3) is associated with a later quitting age [30]. Knowing that there is a genetic role in smoking cessation, individualized treatment is particularly important. Doctors can adapt a precise program for the smokers, especially for those who have failed several attempts at cessation, based to the genotypes of CHRNA5-A3-B4.

Our study also has its limitations. First, this was a hospital-based case control study with limited numbers of samples, and selection bias or recall bias may exist that might affect the results. Secondly, COPD and smoking cessation are influenced by complex factors. In terms of genetic factors, there are multiple gene interaction, and other unobserved variables could alter the results. Finally, our results are only applicable to male smokers; a further study of female smokers is needed.

In conclusion, this study reveals that CHRNA3-A5 and $C H R N B 3-A 6$ are associated with increased successful smoking cessation in COPD smokers, and this could provide a basis for formulation of a specific smoking cessation program. As this study is a hospital-based case control study, a larger multi-center study is needed to confirm the conclusions, and more studies are needed to establish data for different ethnic populations.

\section{ACKNOWLEDGMENTS}

The authors are very grateful to the nurses at the Department of Pulmonary Medicine, Qingdao Municipal Hospital, Qingdao, Shandong Province, PRC, for their help in our data collecting work.

Declaration of Interest. The authors report no conflicts of interest. The authors alone are responsible for the content and writing of this article.

Funding. This study was part of the program on Qingdao Achievement Transformation Project and Science and Technology Benefits Special Project [17-3-3-16-nsh] and Qingdao Shi-nan District Science and Technology Bureau Project [2016-3-016-YY].

\section{REFERENCES}

1. Mathers CD, Loncar D. Projections of global mortality and burden of disease from 2002 to 2030. PLoS Med. 2006; 3(11): 2011-2030.

2. Ding Y, Yang D, Chen W, Chen P, Xie P, Yang H, et al. Smoking and multigenetic index on the risk of chronic obstructive pulmonary disease in the Chinese Li population: A case-control study. Int J Clin Exp Pathol. 2016; 9(4): 4397-4407.

3. Uhl GR, Liu Q-R, Drgon T, Johnson C, Walther D, Rose JE, et al. (See above) Molecular genetics of successful smoking cessation: convergent genomewide association study results. Arch Gen Psychiatry. 2008; 65(6): 683-693.

4. Leventhal AM, Lee W, Bergen AW, Bergen AW, Swan GE, Tyndale RF, et al. (See above) Nicotine dependence as a moderator of genetic influences on smoking cessation treatment outcome. Drug Alcohol Depend. 2014; 138(1): 109-117.

5. Sieminska A, Jassem E, Kita-Milczarska K. Nicotine dependence in an isolated population of Kashubians from North Poland: a population survey. BMC Public Health. 2015; 15(1): 80.

6. Thorgeirsson TE, Geller F, Sulem P, Rafnar T Wiste A, Magnusson KP, et al. A variant associated with nicotine dependence, lung cancer and peripheral arterial disease. Nature. 2008; 452(7187): 638-642.

7. Hung RJ, McKay JD, Gaborieau V, Boffetta P, Hashibe M, Zaridze D, et al. A susceptibility locus for lung cancer maps to nicotinic acetylcholine receptor subunit genes on 15q25. Nature. 2008; 452(7187): 633637. 
8. Amos CI, Wu X, Broderick P, Gorlov IP, Gu J, Eisen $\mathrm{T}$, et al. Genome-wide association scan of tag SNPs identifies a susceptibility locus for lung cancer at 15q25.1. Nat Genet. 2008; 40(5): 616-622.

9. Saccone SF, Hinrichs AL, Saccone NL, Chase GA, Konvicka K, Madden PAF, et al. Cholinergic nicotinic receptor genes implicated in a nicotine dependence association study targeting 348 candidate genes with 3713 SNPs. Hum Mol Genet. 2007; 16(1): 36-49.

10. Zeiger JS, Haberstick BC, Schlaepfer I, Collins AC, Corley RP, Crowley TJ, et al. The neuronal nicotinic receptor subunit genes (CHRNA6 and CHRNB3) are associated with subjective responses to tobacco. Hum Mol Genet. 2008; 17(5): 724-734.

11. Wu C, Hu Z, Yu D, Huang L, Jin G, Liang J, et al. Genetic variants on chromosome $15 \mathrm{q} 25$ associated with lung cancer risk in Chinese populations. Cancer Res. 2009; 69(12): 5065-5072.

12. Niu X, Chen Z, Shen S, Liu Y, Zhou D, Zhang J, et al. Association of the CHRNA3 locus with lung cancer risk and prognosis in Chinese Han population. J Thorac Oncol. 2010; 5(5): 658-666.

13. Wang B, Zhou H, Yang J, Xiao J, Liang B, Li D, et al. Association of HHIP polymorphisms with COPD and COPD-related phenotypes in a Chinese Han population. Gene. 2013; 531(1): 101-105.

14. Kita-Milczarska K, Sieminska A, Jassem E. Association between CHRNA3 and CHRNA5 nicotine receptor subunit gene variants and nicotine dependence in an isolated population of Kashubians in Poland. Med Sci Monit. 2016; 22: 1442-1450.

15. Wen L, Han H, Liu Q, Su K, Yang Z, Cui W, et al. Significant association of the CHRNB3-CHRNA6 gene cluster with nicotine dependence in the Chinese Han population. Sci Rep. 2017; 7(1): 1-10.

16. Papi A, Casoni G, Caramori G, Guzzinati I, Boschetto $\mathrm{P}$, Ravenna F, et al. COPD increases the risk of squamous histological subtype in smokers who develop non-small cell lung carcinoma. Thorax. 2004; 59(8): 679-681.

17. Takiguchi Y, Sekine I, Iwasawa S, Kurimoto R, Tatsumi K. Chronic obstructive pulmonary disease as a risk factor for lung cancer. World J Clin Oncol. 2014; 5(4): 660-666.

18. Sekine Y, Yamada Y, Chiyo M, Iwata T, Nakajima T, Yasufuku K, et al. Association of chronic obstructive pulmonary disease and tumor recurrence in patients with stage IA lung cancer after complete resection. Ann Thorac Surg. 2007; 84(3): 946-950.
19. Lee JY, Yoo SS, Kang H-G, Jin G, Bae EY, Choi YY, et al. A functional polymorphism in the CHRNA3 gene and risk of chronic obstructive pulmonary disease in a Korean population. J Korean Med Sci. 2012; 27(12): 1536-1540.

20. Budulac SE, Vonk JM, Postma DS, Siedlinski M, Timens W, Boezen MH. Nicotinic acetylcholine receptor variants are related to smoking habits, but not directly to COPD. PLoS One. 2012; 7(3): 1-7.

21. Jiménez-Ruiz CA, Andreas S, Lewis KE, Tonnesen P, van Schayck CP, Hajek P, et al. Statement on smoking cessation in COPD and other pulmonary diseases and in smokers with comorbidities who find it difficult to quit. Eur Respir J. 2015; 46(1): 61-79.

22. Breitling LP, Dahmen N, Mittelstrass K, Illig T, Rujescu D, Raum E, et al. Smoking cessation and variations in nicotinic acetylcholine receptor subunits alpha-5, alpha-3, and beta-4 genes. Biol Psychiatry. 2009; 65(8): 691-695.

23. Liu T, David SP, Tyndale RF, Wang H, Zhou Q, Ding $\mathrm{P}$, et al. Associations of CYP2A6 genotype with smoking behaviors in southern China. Addiction. 2011; 106(5): 985-994.

24. Pérez-Rubio G, López-Flores LA, García-Carmona S, García-Gómez L, Noé-Díaz V, Ambrocio-Ortiz E, et $a l$. Genetic variants as risk factors for cigarette smoking at an early age and relapse to smoking cessation treatment: A pilot study. Gene. 2019; 694:93-96. doi: 10.1016/j.gene. 2019.01.036.

25. Japuntich SJ, Leventhal AM, Piper ME, Bolt DM, Roberts LJ, Fiore MC, et al. Smoker characteristics and smoking-cessation milestones. Am J Prev Med. 2011; 40(3): 286-294.

26. Gold AB, Lerman C. Pharmacogenetics of smoking cessation: Role of nicotine target and metabolism genes. Hum Genet. 2012. doi: 10.1007/s00439-0121143-9 [Epub ahead of print].

27. Zuo L, Garcia-Milian R, Guo X, Zhong C, Tan Y, Wang Z, et al. Replicated risk nicotinic cholinergic receptor genes for nicotine dependence. Genes (Basel). 2016; 7(11). doi: 10.3390/genes7110095.

28. Wang Q, Li S, Pan L, Li H, Yang X, Jiang F, et al. Association between variants in nicotinic acetylcholine receptor genes and smoking cessation in a Chinese rural population. Am J Addict. 2016; 25(4): 297-300.

29. Bergen AW, Javitz HS, Krasnow R, Nishita D, Michel $\mathrm{M}$, Conti DV, et al. Nicotinic acetylcholine receptor variation and response to smoking cessation therapies. Pharmacogenet Genomics. 2013; 23(2): 94-103. 
30. Tyndale RF, Zhu AZX, George TP, Paul C, Hawk LW, Schnoll RA, et al. Lack of associations of CHRNA5-A3-B4 genetic variants with smoking cessation treatment outcomes in Caucasian smokers despite associations with baseline smoking. PLoS One. 2015; 10(5): e0128109.

31. Freathy RM, Ring SM, Shields B, Galobardes B, Knight B, Weedon $\mathrm{MN}$, et al. A common genetic variant in the 15q24 nicotinic acetylcholine receptor gene cluster (CHRNA5-CHRNA3-CHRNB4) is associated with a reduced ability of women to quit smoking in pregnancy. Hum Mol Genet. 2009; 18(15): 29222927.

32. Chen L-S, Baker TB, Piper ME, Breslau N, Cannon $\mathrm{DS}$, Doheny KF, et al. Interplay of genetic risk factors (CHRNA5-CHRNA-3-CHRNAB4) and cessation treatments in smoking cessation success. Am J Psychiatry. 2012; 169(7): 735-742. 